\title{
Raffinose family oligosaccharides of lupin (Lupinus albus L. cv multolupa) as a potential prebiotic
}

\author{
C. Martínez-Villaluenga ${ }^{1}$, J. Chicholoska ${ }^{2}$, A. Kliber ${ }^{2}$ and K. Gulewicz ${ }^{2}$ \\ ${ }^{1}$ Instituto de Fermentaciones Industriales, CSIC, C/ Juan de la Cierva 3, 28006 Madrid, Spain and ${ }^{2}$ Department of \\ Animal Physiology and Biochemistry, Agricultural University, Wolynska 35, Poznan 60-637, Poland
}

The beneficial effects on health attributed to prebiotics are directly related to the stimulation of the growth and activities of lactic bacteria and bifidobacteria in the human intestine ${ }^{(1)}$. Moreover, proliferation of these beneficial bacteria contributes indirectly to the stimulation of the immune system through IgA and IL (IL1, IL6 and $\gamma$-IL) production ${ }^{(2-6)}$.

Raffinose family oligosaccharides ( $\alpha$-galactosides) are non-digestible oligosaccharides with an extent of polymerization of three to six molecules. These compounds are $\alpha(1 \rightarrow 6)$ galactosides linked to the $\mathrm{C}-6$ of the glucose moiety of sucrose, which are abundant in legume seeds of which lupins are the richest source $(120 \mathrm{~g} / \mathrm{kg} \text { seed dry weight })^{(7)}$. These oligosaccharides can be easily extracted from the seeds and further purified ${ }^{(8)}$ to be used as ingredients during the manufacture of different functional foods. In ovo studies have demonstrated the potential prebiotic effect of $\alpha$-galactosides derived from lupin seeds ${ }^{(9)}$.

In the present work the evaluation of $\alpha$-galactosides as prebiotics was carried out in vivo using an animal model. These results were compared with those obtained for pure raffinose, and also commercial fructo-oligosaccharides (FOS) and inulin. Doses of $15 \mathrm{mg} / 100 \mathrm{~g}$ body weight were administered orally once daily to Wistar rats for $23 \mathrm{~d}$. The numbers of faecal bifidobacteria were estimated at days 0,10 and 23. Oligosaccharide administration for all experimental groups showed gradual increases $(P \leq 0.05)$ in faecal bifidobacteria with the duration of the experiment, reaching the highest value after the longest time period. The numbers of faecal bifidobacteria in rats after administration of raffinose family oligosaccharides (RFOS) from lupin seeds were comparable with those found with pure raffinose and commercial fructo-oligosaccharides and inulin (Figure).

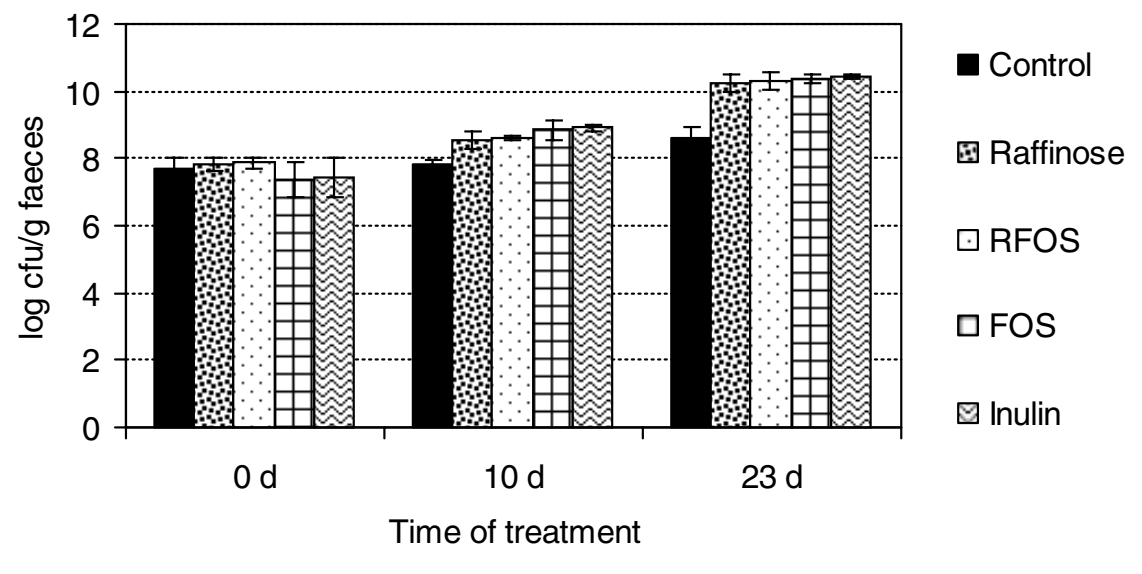

Figure. Effect of oligosaccharide administration $(15 \mathrm{mg} / 100 \mathrm{~g}$ body weight $)$ on numbers of faecal bifidobacteria.

Thus, this in vivo study has shown that $\alpha$-galactosides from lupin stimulate bifidobacterial growth and indirectly immune response. Nevertheless, subsequent intervention studies are needed to establish definitive conclusions.

This work is a result of a bilateral scientific cooperation joint project between Poland (Polish Academy of Sciences) and Spain (CSIC).

1. Gibson GR \& Roberfroid MB (1995) Br J Nutr 125, 1401-1412.

2. McCraken VJ \& Gaskins HR (1997) In Probiotics: A Critical Review, pp. 85-111 [GW Tannock, editor]. Norwich, Norfolk: Horizon Scientific Press.

3. Kato I (1997) Healthist Special anniversary ed., 60-66.

4. Ishikawa H. (1997) Healthist Special anniversary ed. 787-789.

5. Ballongue J (1993) Bifidobacteria and Probiotic Action, pp. 357-428 [S Salminen and A von Wright, editors] New York: Marcel Dekker.

6. Isoulari E (2000) Hosp Med 61, 6-7.

7. Martínez-Villaluenga C, Frías J \& Vidal-Valverde C (2005) Food Chem 91, 645-649.

8. Martínez-Villaluenga C, Frías J, Gulewicz K \& Vidal-Valverde C (2004) J Agric Food Chem 52, 6920-6922.

9. Martínez-Villaluenga C, Wardeńska M, Pilarski R, Bednarczyk M \& Gulewicz K (2004) Folia Biol (Krakow) 52, $135-142$. 